\title{
MODELING OF STORM SURGE AND FLOOD HAZARD AROUND LAGUNA DE BAY, PHILIPPINES
}

\author{
Paul C. Rivera ${ }^{1}$ and Emiterio C. Hernandez ${ }^{2}$ \\ ${ }^{1}$ Hymetocean Peers Co., Antipolo City, Philippines \\ ${ }^{2}$ Laguna Lake Development Authority, Quezon City, Philippines
}

\begin{abstract}
One of the biggest problems in Laguna de Bay, Philippines is the occurrence of shoreland flooding with various degree of severity. Flood levels in adjacent low-lying areas may vary depending on the combined influence of excessive rainfall, river discharges and storm surge due to strong winds. The hydrodynamic model Delft-FLOW was used to assess the perennial flooding problem around the lake. It was shown by the hydrodynamic model that large shoreland areas to the western, southern and eastern parts of the lake remain vulnerable to flooding. A very long strip of shoreline of about half the lake perimeter requires protection from flood waters. The inundation distance from the shoreline is estimated by the model to range from $500 \mathrm{~m}$ to as far as 4,000 $\mathrm{m}$ depending on the strength and duration of stormy winds and rainfall that act in combination to elevate the water level from the water level datum of $12.5 \mathrm{~m}$ elevation. The vulnerable areas covering a total of over 28,000 hectares are made up of agricultural and populated communities. Without any mitigation measure in place, flooding will always recur during the wet season. The duration of flooding of these areas may be temporary but can range from few days to several weeks depending on the period and duration of the southwest monsoon rains that accompany the storm. It is therefore recommended that a dike that will also serve as a lakeshore road, be designed and constructed to protect the lowlying areas. The economic implication of flooding in terms of agricultural and property losses is enormous and a flood mitigation measure must be set in place.
\end{abstract}

Keywords: hydrodynamic modeling; flood hazard; Laguna de Bay 


\subsection{INTRODUCTION}

Laguna de Bay is a large, shallow, freshwater lake situated southeast of the highly urbanized metropolitan district of Manila, Philippines (see Figure 1). Close to 90,000 ha in total area at a mean water level datum of $11.32 \mathrm{~m}$, a large part of the lake remain submerged underwater even during the dry season. A Decision Support System (DSS) consisting of various modules of the Delft3D Modeling Suite has been established during the Dutch-funded project Sustainable Development of the Laguna de Bay Environment (SDLBE) project by the WL|Delft Hydraulics of the Netherlands for the conduct of research on hydrodynamics and water quality of Laguna de Bay. The hydrodynamic model Delft-FLOW was used to address the flooding problem in the lake.

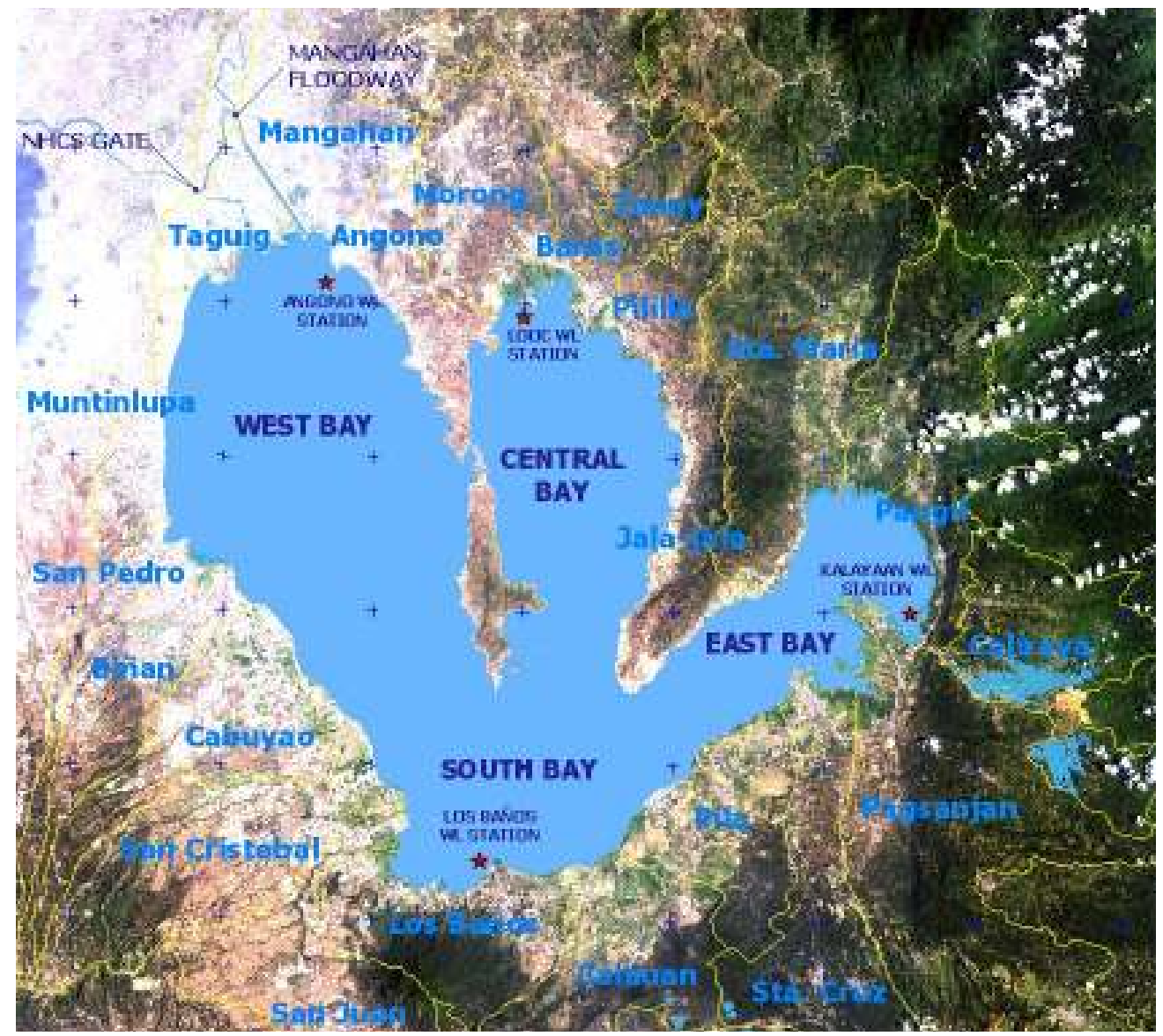

Figure 1. The Laguna de Bay water system (from Hernandez E.C., 2006)

\subsection{Objectives of the Research Study}

The main objective of the study is to apply the hydrodynamic model and other sub-models of the existing Decision Support System (DSS) to carry out flood hazard studies in Laguna de Bay. In particular, the hydrodynamic model Delft-FLOW is used to assess the perennial flooding problem around the lake using observed hydro-meteorological conditions within and around the lake system and its tributaries. 


\subsection{COMPUTATIONAL DOMAIN AND MODEL IMPLEMENTATION}

\subsection{Modeling Approach}

To determine the potential flooding of upper shoreland areas in Laguna de Bay during high water level, a computational grid that encompasses the $15 \mathrm{~m}$ water level datum was prepared as shown in Figure 2. The average water depth of the lake is about $2.5 \mathrm{~m}$, with a large part of its northern and eastern portions under $1.0 \mathrm{~m}$ of water during the dry season (SDLBE 2001). Using the QUICKIN program under Delft3D and making use of depth soundings collected by the National Institute of Geological Sciences (NIGS 1999), the lake bathymetry is shown in the Figure 3 below. Depth extrapolation in the upper shoreland areas was done by the present technical staff of Laguna Lake Development Authority (LLDA) under the Dutch-funded SDLBE Project of 2000-2003. The extrapolation carried out was considered necessary to determine the potential flooding of low-lying areas under combined action of extreme winds, rainfall and river discharges.

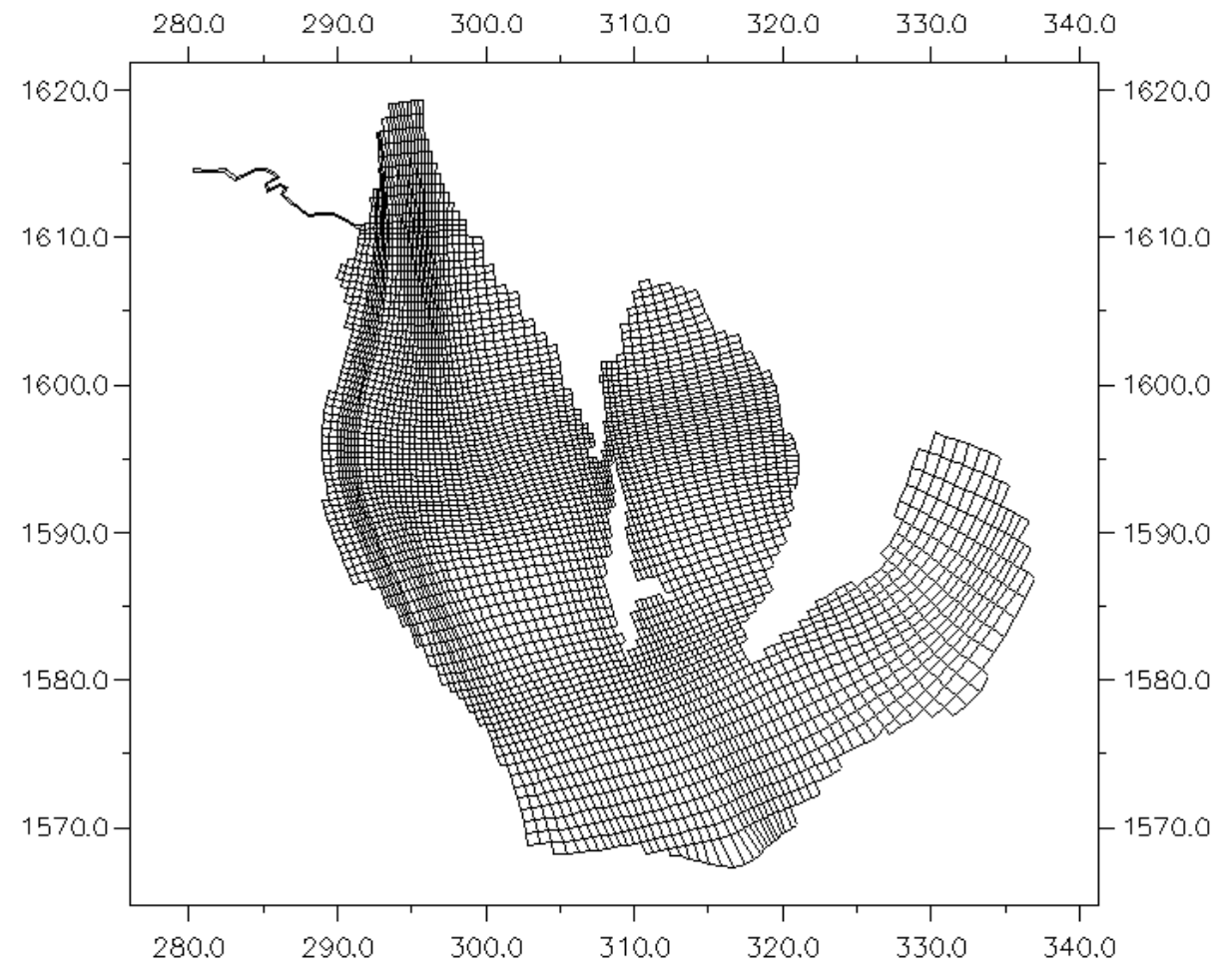

Figure 2. Model grid for the present hydrodynamic and flood simulations. 


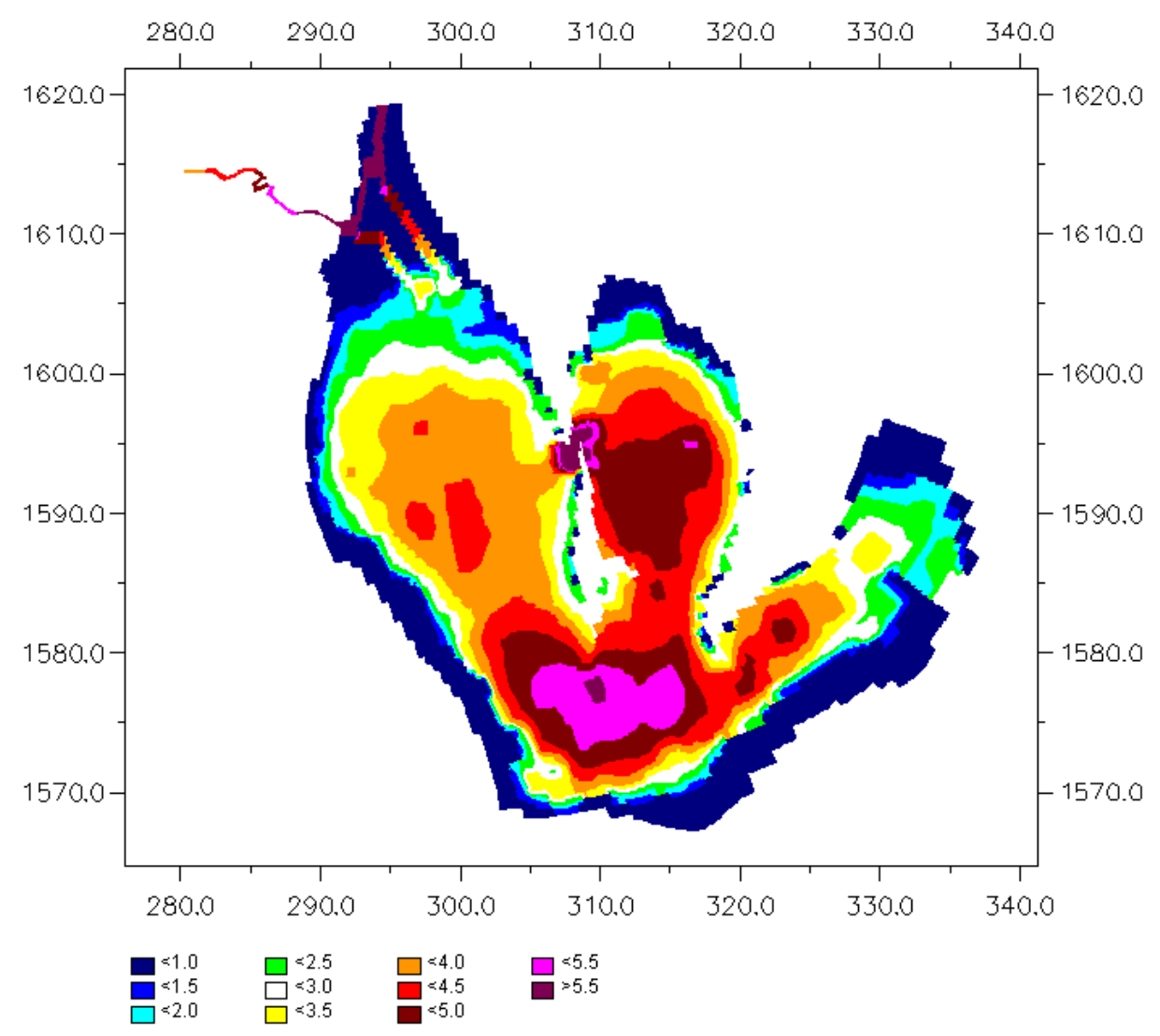

Figure 3. Smoothed bathymetry of the computational domain of Laguna de Bay

An interesting feature of the lake is the occurrence of a saline water intrusion during the dry season. The Pasig River, which drains the lake towards Manila Bay to the northwest, reverses its flow during low water levels in the lake. While this is temporary that occurs during extremely dry years, it contributes to the increased salinity of the lake waters that affects its water quality, primary productivity, and overall ecology. The inclusion of the Pasig River in the computational model is therefore necessary. This is shown by the small strip of water towards the northwest part of the bay.

One of the biggest problems of the lake at present is the perennial flooding that occurs in many low-lying populated areas. As the topographic slope of shoreland areas towards the west (including northwest) and to the south and eastern parts is not very steep but gradually increasing, occasional flooding from extreme rainfall and lake water set-up (or surges) may occur during storms. The magnitude and extent of flooding is determined by the magnitude of stormy winds and rainfall during the wet season or southwest monsoon season. Using the hydrodynamic module Delft3D-Flow, this flooding problem is addressed in the present study. Accurate prediction of the maximum water levels that may occur in any part of the lake is important for planning and decision-making purposes.

\subsection{Model Input Data}

There are number of important information and data that are needed to run the DSS models. For hydrodynamic simulations within the computational domain shown in Figure 2, various hydro-meteorological data are needed. To address the possible high water level that may occur 
anytime during flooding, the stormy condition of 1995 was modeled and the resulting flooding analyzed. The 1995 case was deemed appropriate due to the occurrence of a strong typhoon during the month of November where water level is still high in the lake. The baseline information for that year with an extreme flood scenario is complete and therefore presents a suitable candidate for analyzing the potential flooding problem in the lake surroundings. The hydrological data include river discharges from 24 tributaries. These were generated by the hydrological model (SAC-SMA) within the present DSS of LLDA and are shown in Figure 4. In addition to this, the abstraction of water from the lake which contributes to overall water variation during the years, are also included. There are ten (10) major irrigation sites where lake water is pumped regularly. This includes the agricultural areas to the north and eastern parts of the lake. The domestic water usage in the western part of the lake is regularly supplied under MWSS-Ayala and also requires regular abstraction from the lake. In addition to this, water abstraction during the dry-season is also required by the CBK Hydropower Company in Kalayaan, Laguna towards the eastern part of the lake. Furthermore, groundwater interaction is also included as this may add to the overall water level variation in the lake. It should be noted that there are a number of springs especially in the southern part of the lake.

In addition to the hydrological data needed to run the hydrodynamic model, a number of important meteorological data are needed. This includes hourly wind speed and direction, daily precipitation and evaporation. Data on wind speed and direction for a stormy condition are shown in Figures 5. These meteorological forcings were obtained from a nearby weather station, the Ninoy Aquino International Airport (NAIA). The precipitation data for the lake using lake-averaged precipitation in combination with spatially constant evaporation were assumed. The other meteorological variables such as humidity, temperature, pressure were assumed constant in time and space. Daily time series of rainfall from 15 stations around the lake has been used in the model computations. These are shown in Figure 6. Regarding lake evaporation, the daily pan evaporation data for Los Baños located to the southern part of the lake were used. The actual evaporation which is considered equal to the potential evaporation was determined using a constant pan coefficient of 0.7 .

\subsection{RESULTS OF HYDRODYNAMIC SIMULATIONS}

The perennial problem of flooding in Laguna de Bay has always been experienced by shoreland dwellers during the rainy season. While rain and high river discharges are the usual culprit in the flooding of low-lying areas, the impact of wind-driven flows and wave set-up often appears as a storm surge that can inundate and flood low-lying areas where stormy wind is directed. This surge problem is often experienced in low-lying coastal areas during storms (e.g. Hurricane Katrina case). The chance that it occurs in Laguna de Bay is always there due the shallowness of the lake and the high percentage of typhoon passage within the Philippines (e.g. average of 20 typhoons per year). The Delft3D-Flow module was used to reconstruct and delineate the potential areas that may be flooded during stormy conditions. In order to ensure the reliability of the hydrodynamic model predictions in the study area, model calibration with historical data was carried out for several months. The result of the model calibration is shown in the figure below.

It can be seen that there is a close agreement between the model results and the measured water level in 3 gauging stations around the Laguna de Bay region. A more detailed discussion of the model calibration is presented in Hernandez (2006). 


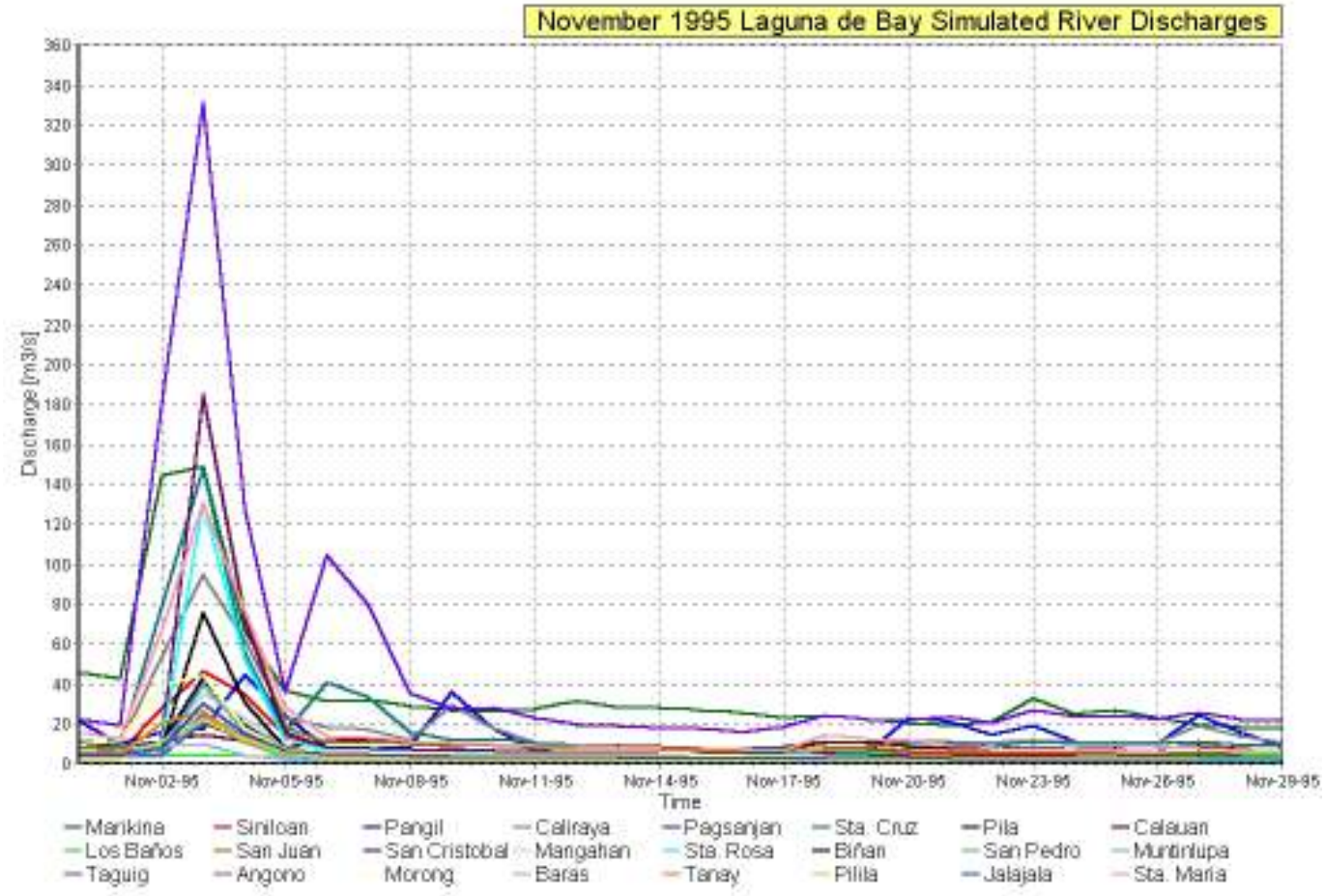

Figure 4. River discharges around Laguna de Bay estimated using SAC-SMA.

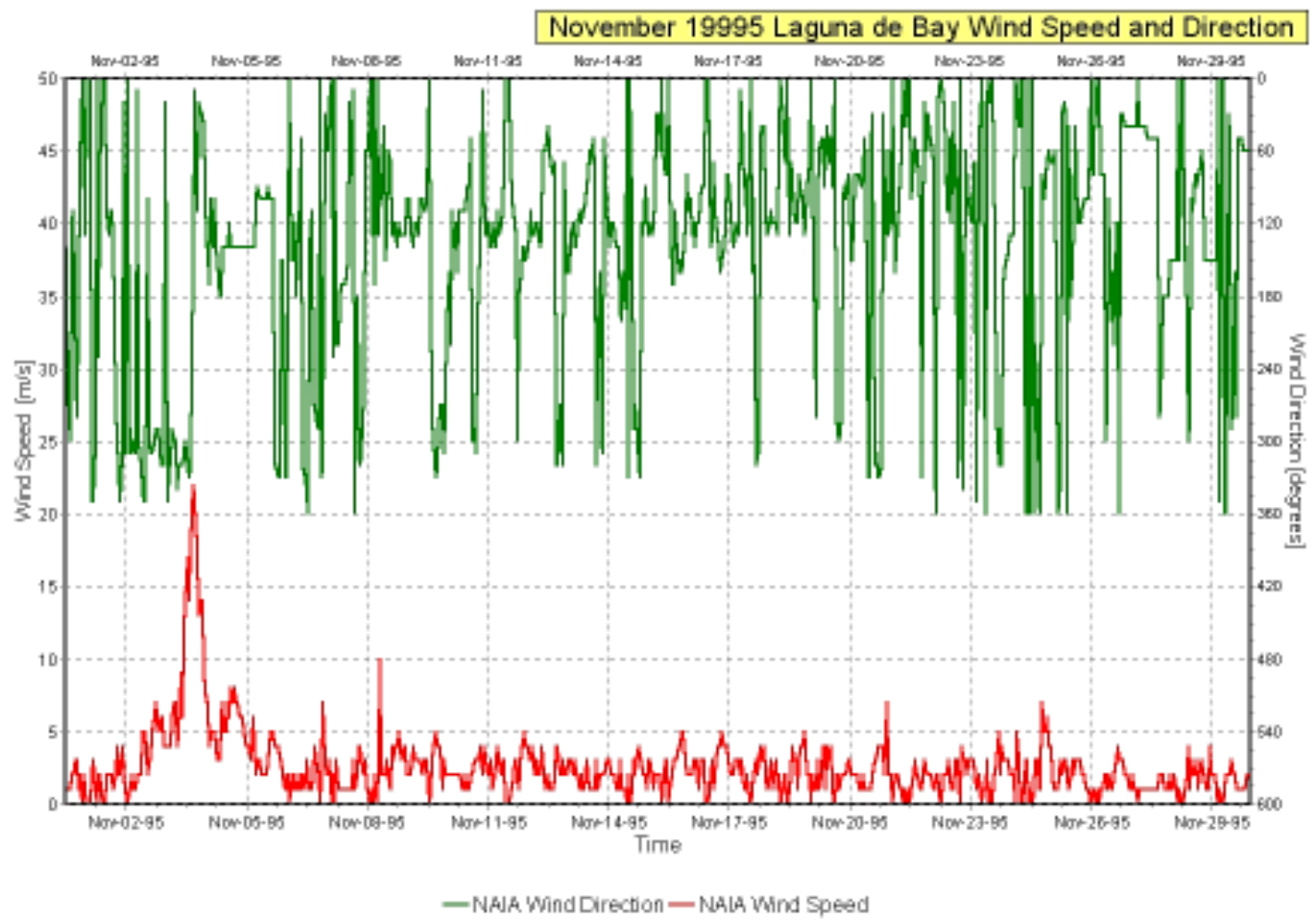

Figure 5. Wind speed and direction during a storm used in flood modeling. 


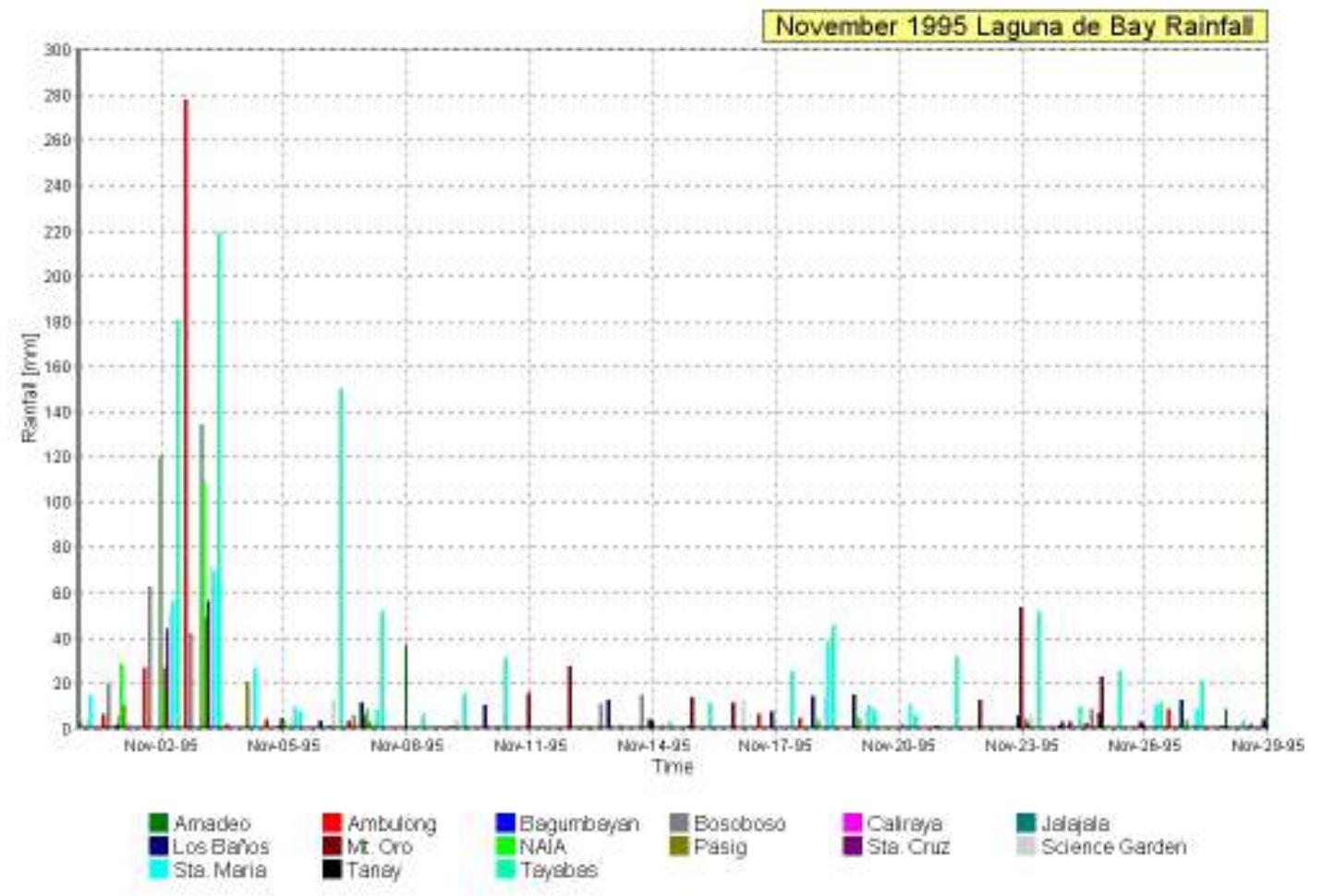

Figure 6. Rainfall during a storm in 1995 used in modeling flood vulnerability of Laguna de Bay.

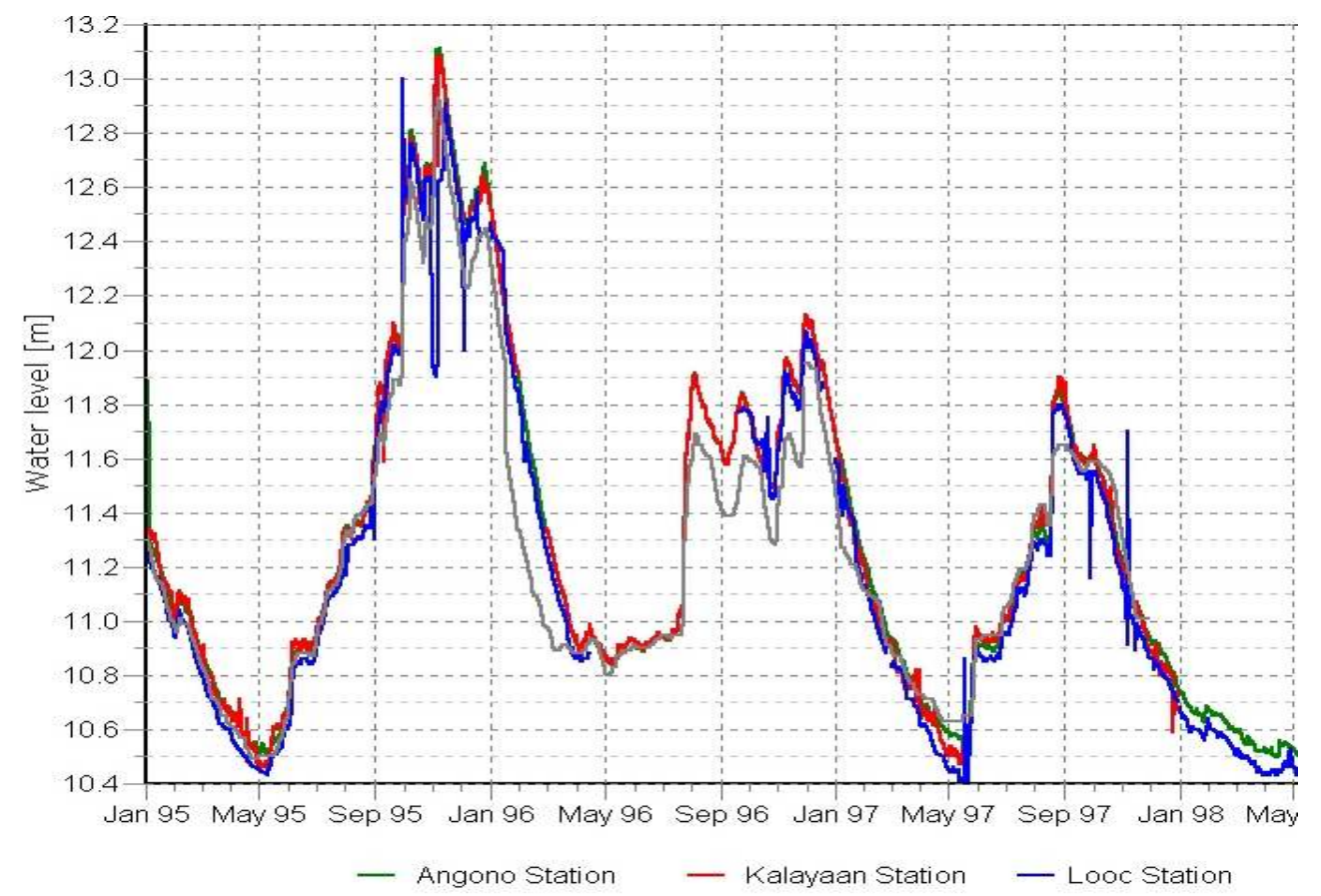

Figure 7. Comparison of observed and modeled lake water level in Laguna de Bay. 


\subsection{Computed Flood Inundation}

Inundation simulation is a difficult hydrodynamic problem (Delft3D-Flow Users Manual). In order to treat the submergence of low-lying areas during floods, the height of land areas above the water level were included as input into the bathymetric data. This is because the flooding algorithm considers the total water level as the initial height of land above the mean water level plus the height of the flood wave in the simulation of flooding. The vulnerability of shoreland areas to flood waters therefore is higher if the land area is low as compared to the mean water level. If an area is high above the mean water level, the chance of being inundated is lower. The presence of hills and mountains in some areas to the north of the lake appears to be fortunate in this case.

The model results during typhoon occurrence and passage within Laguna de Bay are shown in Figures 8-15. When the typhoon is approaching the lake, the water level rises towards the southern and eastern parts as shown in Figures 8-10. Higher water levels are shown in dark colors. As the typhoon center passed over the lake, a transition in the water level rise is shown in Figures 11-12. With stormy winds from the south and southeast, the water level rose in the northern parts of the lake. As shown by the dark colors, many shoreland areas of west bay were submerged during that wind transition. However, due to recurvature of the storm path from northwestward to northeastward, a change in the wind direction from the northeast posed a direct threat towards the southwestern parts of the lake. As shown by the dark contours in Figures 13-14, many parts of South Bay and the West bay were submerged with lake waters after the typhoon changed its path. This is clearly a storm scenario that can inundate many areas of the lake. Well-behaved storms may not pose the same flooding hazard as the November 1995 storm directly caused.

To determine the extent of flooding, a map of the maximum water levels during the stormy period was derived from the numerical results by taking the maximum of several succeeding outputs. Hourly outputs were selected that represent the time when the storm was directly causing floods in the shorelands of the Laguna de Bay. The Maximum Envelop Of Water (MEOW) is shown in Figure 16. The darks areas represent the shoreland areas that can be flooded during a storm. These include a large part to the southwest portion of the lake, the northern portion of west bay, and the shoreland areas of East Bay. Residents have always complained about the flooding that occurs in these areas during stormy conditions. A flood hazard map is also shown in Figure 17 to delineate those areas around the lake that may be flooded during storms. As shown, the shoreland areas with light blue colors are at high risk of being flooded. Clearly, many areas around the lake, especially the low-lying shoreland areas in the West, South and East Bays are prone to be submerged by flood waters. These areas at risk of being flooded are already above the $12.5 \mathrm{~m}$ datum and are not usually submerged without storms. The strong winds from the storm, coupled with the strong rainfall and river discharges, virtually affect all low-lying areas around the lake. The duration of flooding of these areas may be temporary but can range from several hours to several weeks depending on the period and duration of the southwest monsoon rains that accompany the storm. 


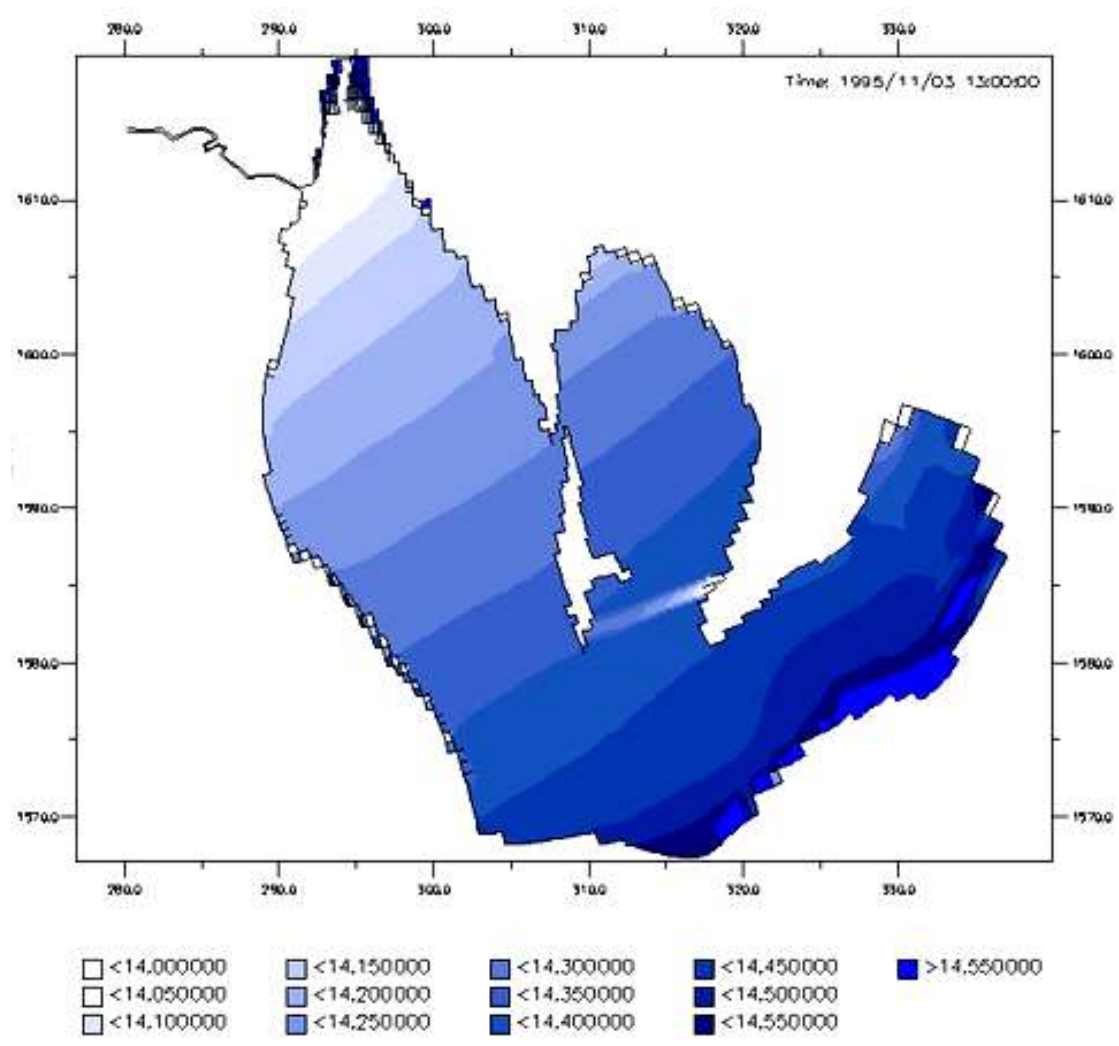

Figure 8. Water level (m) in Laguna de Bay during a typhoon with strong winds from the northnorthwest.

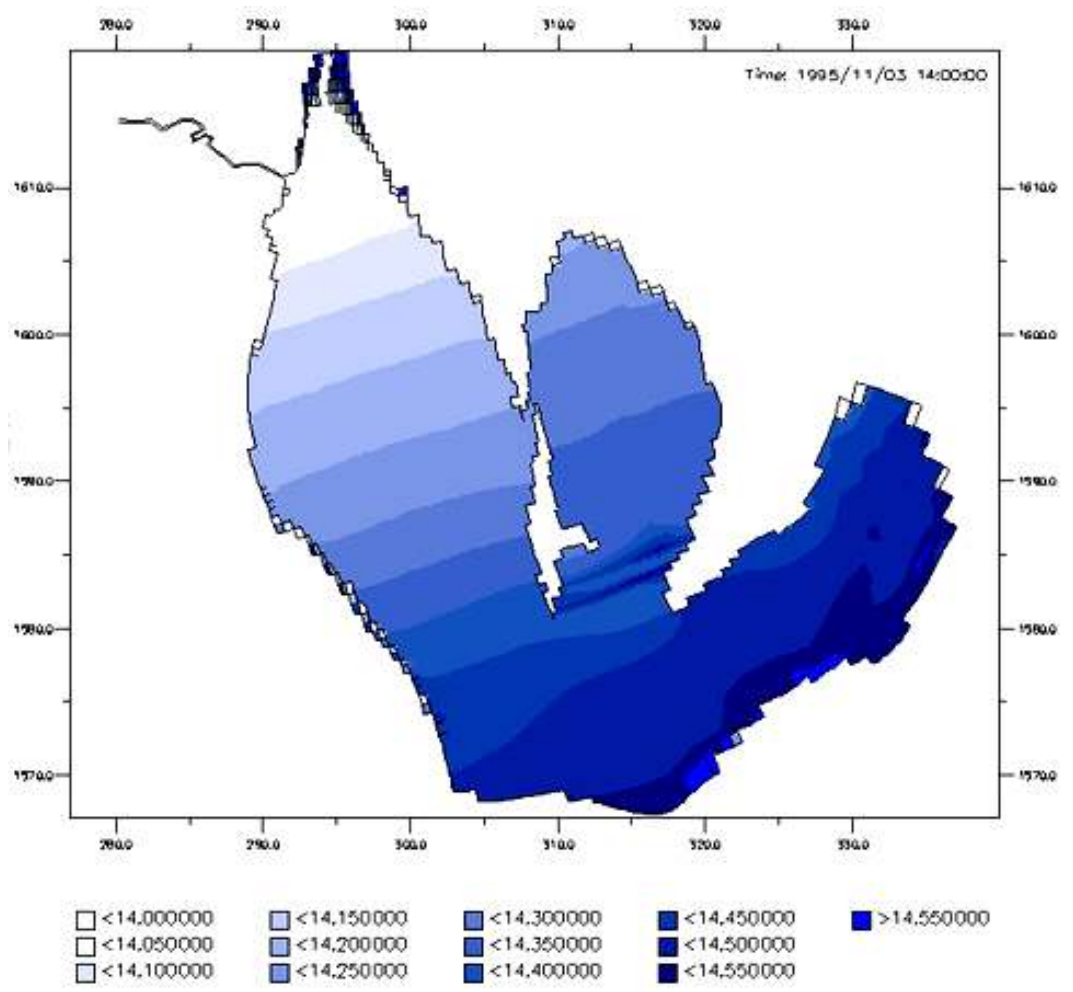

Figure 9. Water level (m) in Laguna de Bay during a typhoon with strong winds from the north. 


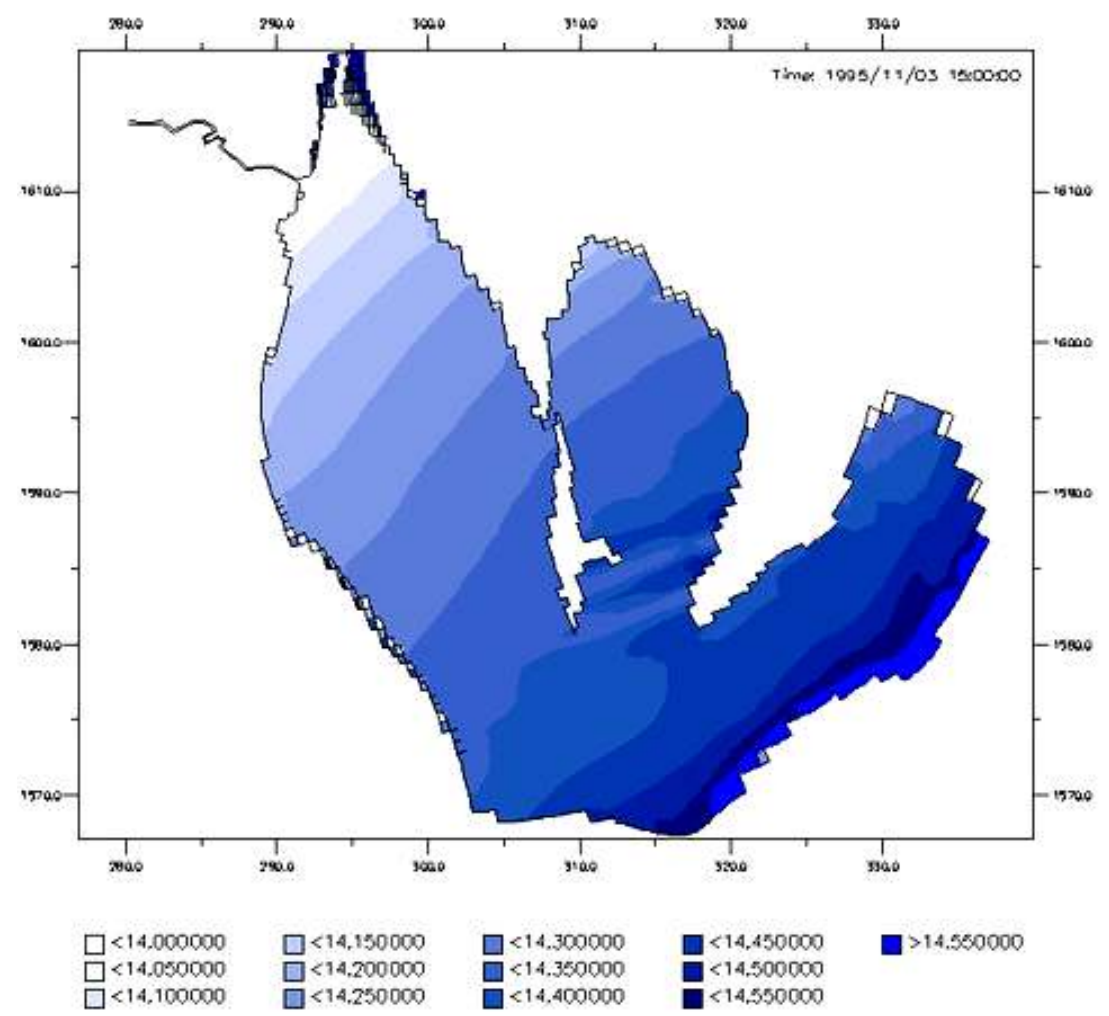

Figure 10. Water level (m) in Laguna de Bay during a typhoon with strong winds from the northwest.

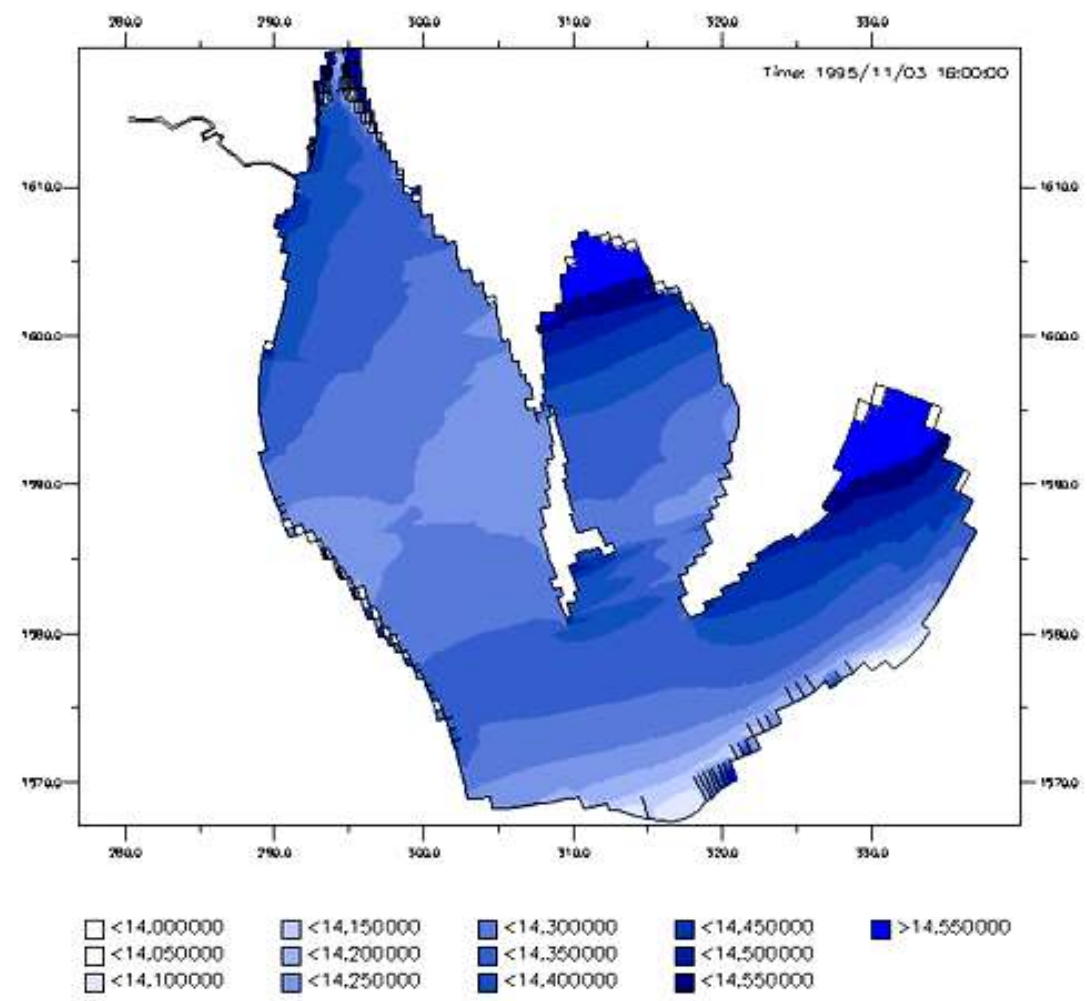

Figure 11. Flood level (m) in Laguna de Bay during a typhoon with strong winds from the south. 


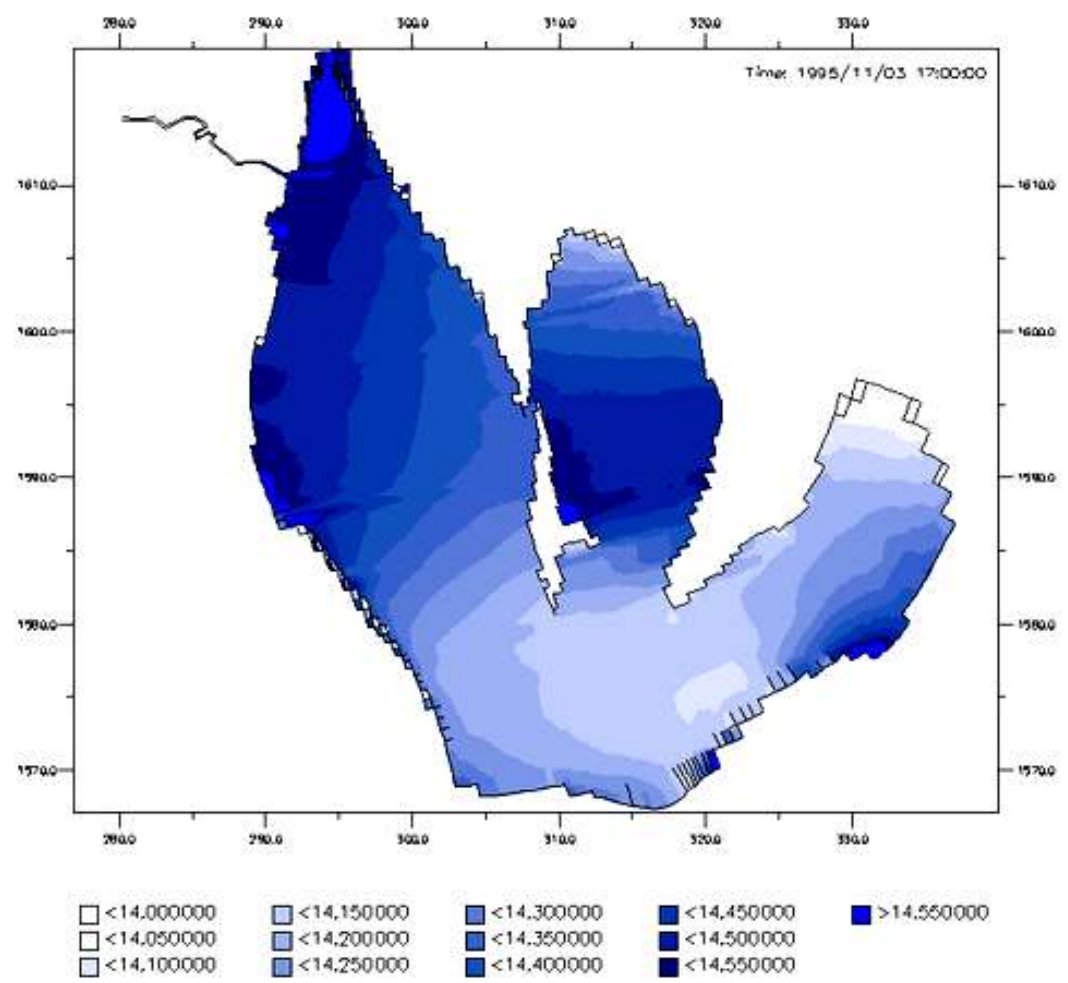

Figure 12. Water level (m) in Laguna de Bay during a typhoon with strong winds from the southeast.

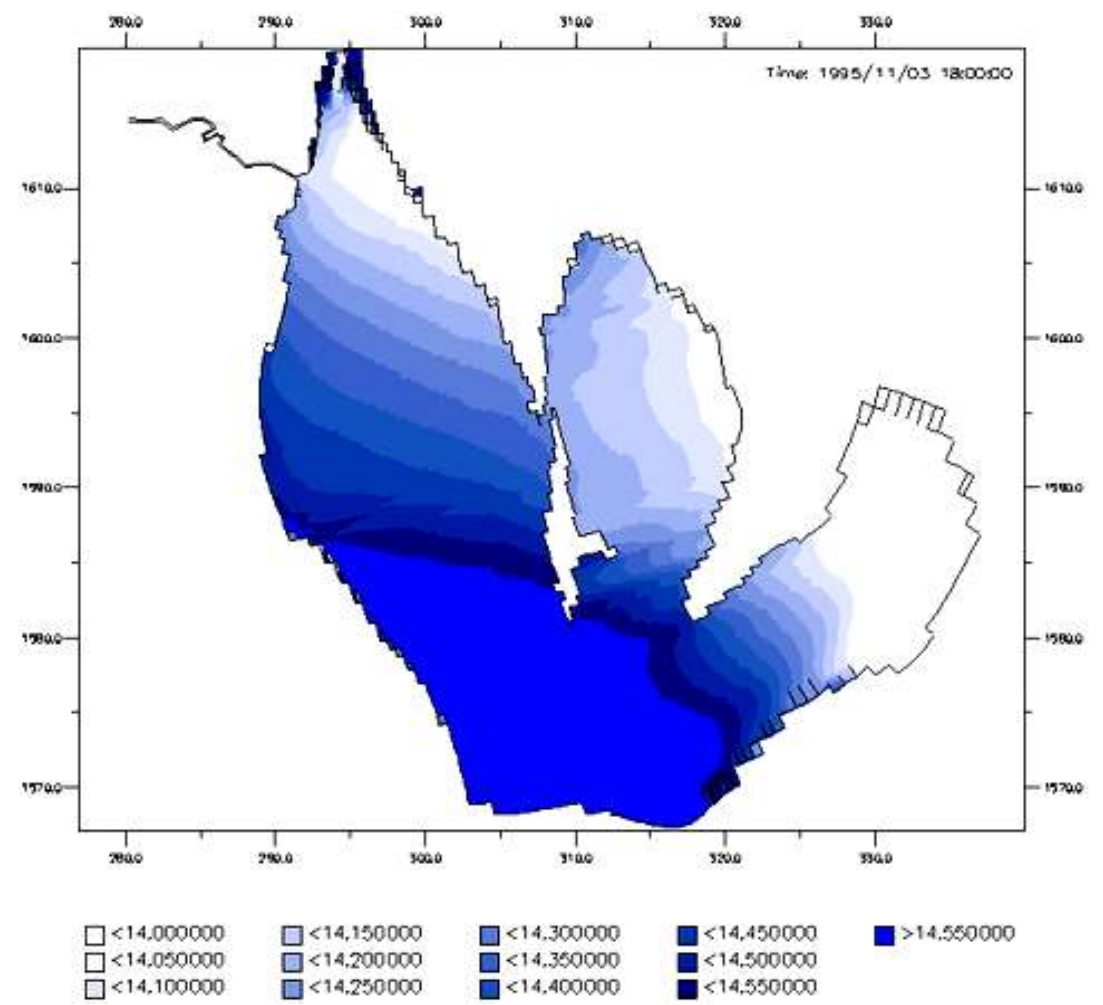

Figure 13. Water level (m) in Laguna de Bay during a typhoon with strong winds from the northeast. 


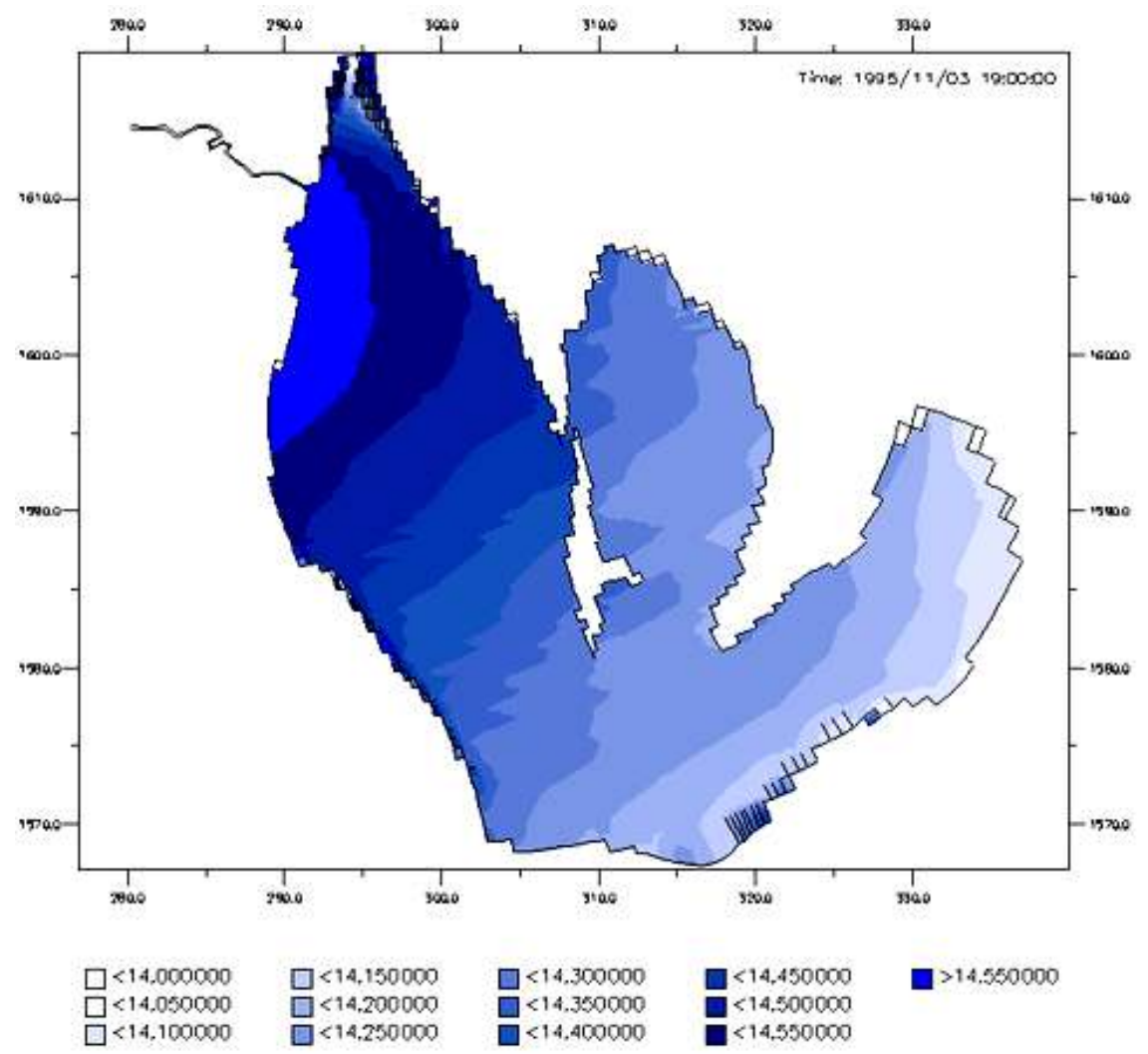

Figure 14. Water level (m) in Laguna de Bay during a typhoon with strong winds from the east.

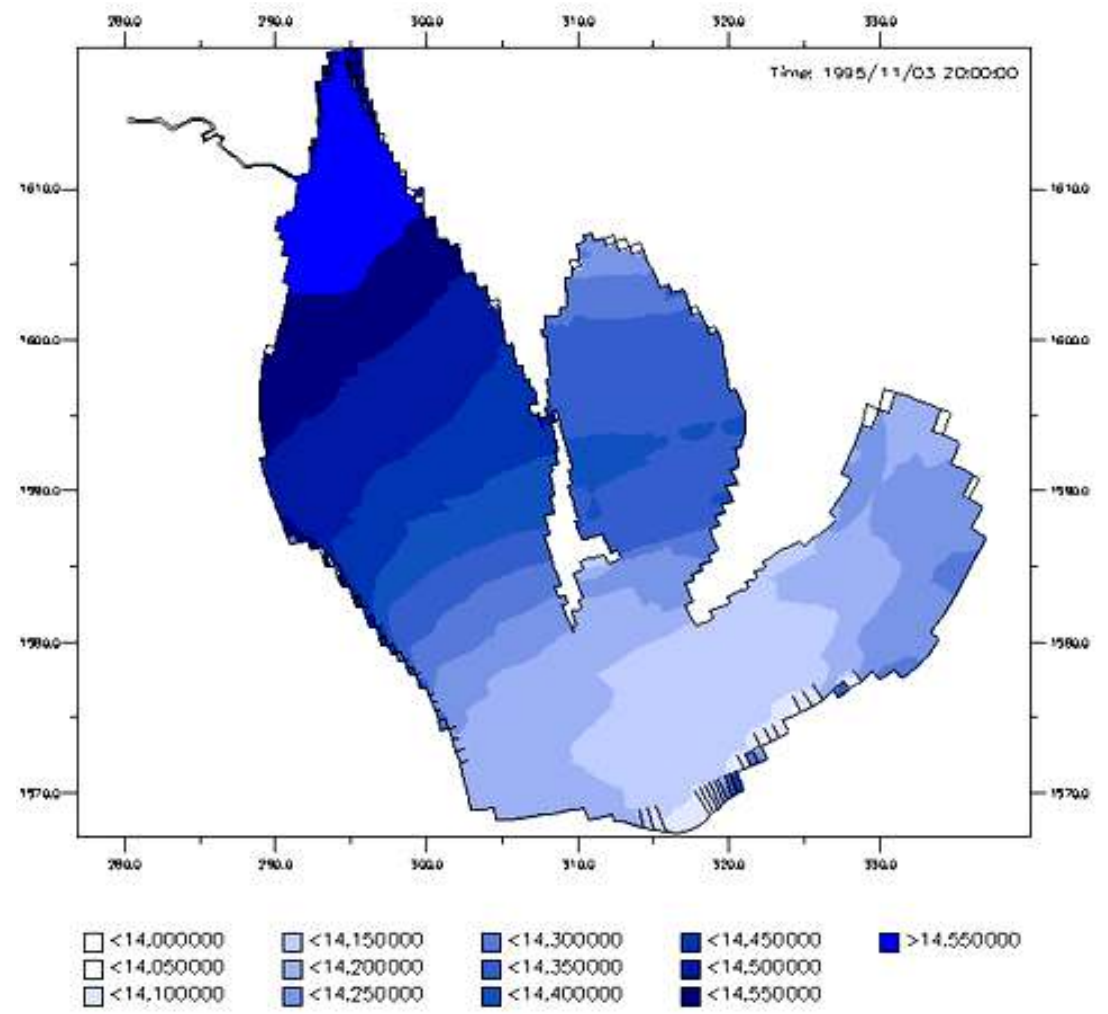

Figure 15. Water level (m) in Laguna de Bay during a typhoon with strong winds from the south (after storm passage over the lake). 


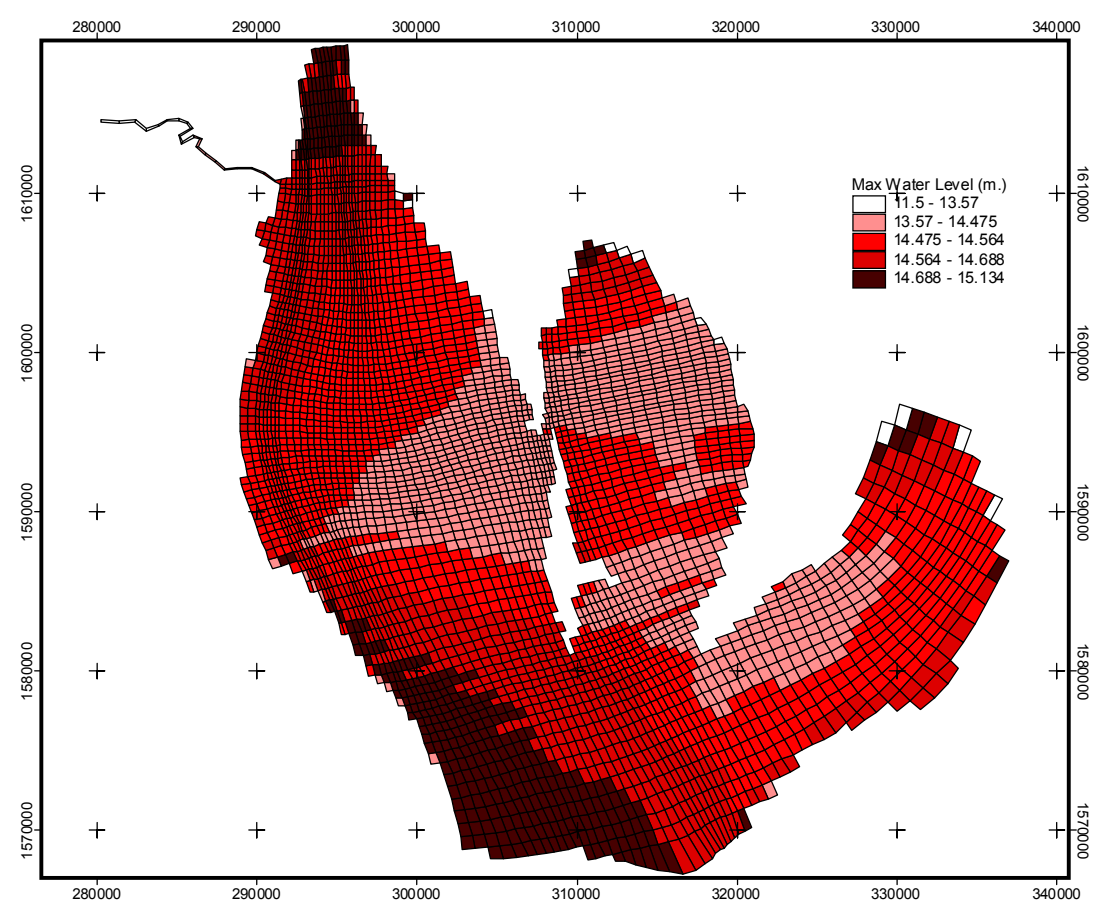

Figure 16. Simulated maximum water level (storm surge) in Laguna de Bay during stormy condition.

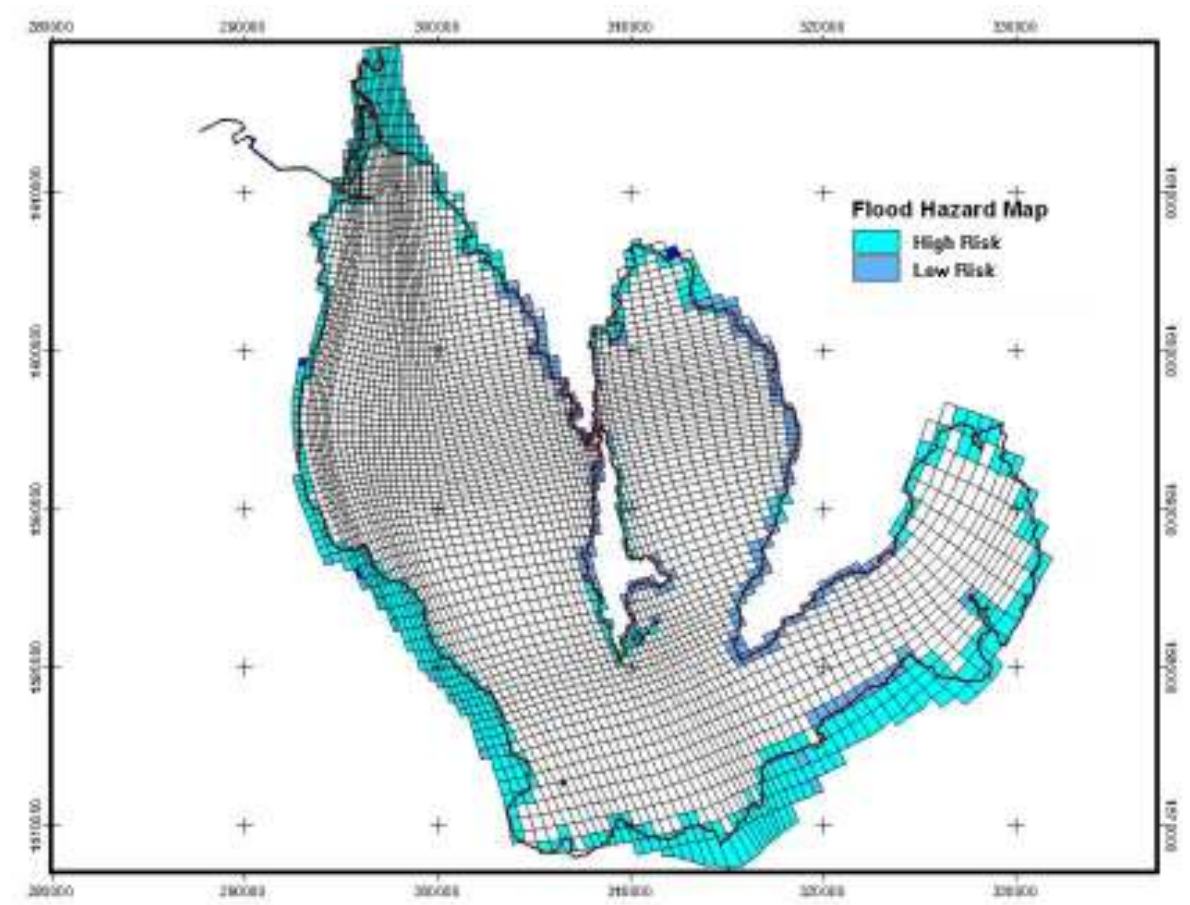

Figure 17. Flood hazard map around Laguna de Bay during stormy conditions with extreme winds, rain and river discharges.

Using ArcView, it is estimated than an area of about 28,970.1 hectares in the low lying areas around Laguna de Bay is vulnerable to flooding. This is shown by the blue areas plotted in Figure 16 . This is about $20-24 \%$ of the total lake area (based on the $15 \mathrm{~m}$ water level datum). It should be noted that the total lake area within the $15 \mathrm{~m}$ water level datum is higher than the 
90,000 hectares average area at $10.5 \mathrm{~m}$ water level. ArcView-GIS estimated about 119,530.1 hectares total lake area at the $15 \mathrm{~m}$ water level.

The vulnerability to flooding of the estimated 28,970 hectares is of course dependent on the storm conditions. This area has been estimated from a combined rainfall, river discharges, and winds during strong storm conditions. Due to extreme rainfall and river discharges alone, the vulnerable area can be much lower (e.g. about half of the vulnerable area). However, the contribution of the strong winds pushing the lake waters to low-lying areas can account for the other half of the vulnerable area. This is a unique problem occurring in Laguna de Bay and not found in deep lakes. This phenomenon known as storm surge with subsequent seiching (e.g. periodic rise and fall of the water level created by the stormy wind) has been documented in many lakes and shallow coastal waters and has been observed to occur in the Laguna Lake by witnesses. Due to its large surface area of the lake and its shallow waters, it is possible to have a storm surge in Laguna Lake waters.

It is shown in the figure above that there is a very long strip of shoreland areas as shown by the blue shades that need to be protected from flood waters of Laguna de Bay. Most of these are confined in the low-lying areas of West, East and South Bays. A very long strip of shoreline of about half the lake perimeter should be protected from flood waters. This stretches from West Bay to East Bay. The inundation distance from the shoreline is estimated to range from $500 \mathrm{~m}$ to as far as $6000 \mathrm{~m}$ depending on the strength and duration of stormy winds and rainfall that act in combination to elevate the water level from the no-flooding $12.5 \mathrm{~m}$ elevation.

\subsection{Flood Mitigation}

Mitigating the effect of flood is necessary because of the associated loss of life and property in cases where no action is taken by the Local and National Government Authorities. Fortunately enough in Laguna de Bay, flood mitigation has been started by the Department of Public Works and Highways (DPWH) through financing by the Japan Bank for International Cooperation (JBIC). A dike with a total length of about $20 \mathrm{~km}$ is being constructed under this project in the northern part of West Bay stretching from Taguig to Angono in northern West Bay. This has been shown by the model results to be particularly vulnerable to flooding during stormy conditions. This lakeshore dike is built not only to protect the vulnerable low-lying areas but also to serve as a transport route between there areas.

It is shown by the model results that a large shoreland area from the West Bay towards the East Bay is potentially submerged by flood waters during stormy conditions. It is therefore worthwhile and a wise decision to design and build a long flood protection dike in these areas to save the properties, lives, and products from being submerged of flood waters. Such dikes can also be used as transport routes or lakeshore roads between the shoreland municipalities. Slowly, dike construction can be started from west to east along the southern shoreland areas before all the remaining areas for construction are clogged with illegal settlers. The economic implication is enormous when all the shoreland areas are occupied by slum dwellers.

The proposed lakeshore road as a flood protection dike does not contradict the present LLDA policy on banned reclamation or lake filling. This is because the proposed dike will be strictly aligned within or outside the $12.5 \mathrm{~m}$ elevation datum which is normally exposed. This datum has been regarded in the flood modeling analysis as the 'outward limit' of the submerged portion of the lake. Outside this elevation, the flooding problem remains as a big threat to the lakeshore/shoreland communities especially during storms and extreme rainfall events and therefore its effect on the lives and properties of affected populace should be considered. 
There is of course the immediate adverse impact on the agricultural and industrial sectors which are concentrated near the lake. The economic implication on these sectors will be immense as well if no flood mitigation measure is taken into consideration.

The proposed dike construction can also have a positive economic impact. Transportation of goods from the congested metropolis and vice versa will become easier and faster as well. In addition, the lakeshore dike can have an open space adjacent to the lake which can be used as a park. The arch-long flood protection dike in the southern lakeshore areas may have the same potential for economic growth if designed very well. The view of the lake with its natural scenery can therefore have a good economic potential. Problems on pollution loads may also be reduced in the long term.

\subsection{CONCLUSIONS AND RECOMMENDATIONS}

One of the biggest problems now in Laguna de Bay is the occurrence of flooding with various degree of severity in low-lying areas. Flood levels in these areas may vary depending on the combined influence of excessive rainfall, river discharges and storm surge due to strong winds. The hydrodynamic model Delft-FLOW was used to assess the perennial flooding problem around the lake. It was shown by the hydrodynamic model that there is a very long strip of shoreland areas around Laguna de Bay that need to be protected from flood waters. Most of these are confined in the low-lying areas of West, East and South Bays. A very long strip of shoreline of about half the lake perimeter should be protected from flood waters. The inundation distance from the shoreline is estimated to range from $500 \mathrm{~m}$ to as far as $4,000 \mathrm{~m}$ depending on the strength and duration of stormy winds and rainfall that act in combination to elevate the water level from the water level datum of $12.5 \mathrm{~m}$ elevation. The vulnerable areas are made up of agricultural and populated communities. Without any mitigation measure in place, flooding will always recur during the wet season. The duration of flooding of these areas may be temporary but can range from few hours to several days depending on the period and duration of the southwest monsoon rains that accompany the storm. It is therefore recommended that a dike similar to the dike being constructed now in the northern part of West Bay, be designed and gradually constructed. Slowly, dike construction should be started from west to east (or east to west) along the southern shoreland areas before all the remaining areas for construction are clogged with illegal settlers. The economic implication of flooding in terms of agricultural and property losses is enormous and a flood mitigation measure must be set in place.

\subsection{REFERENCES}

Delft Hydraulics (1999). DELFT3D-FLOW. USER Manual.

Hernandez, EC (2006). Hydrodynamic Modeling of Laguna de Bay using Delft3D-FLOW (to appear in the December 2006 issue of the Philippine Engineering Journal)

Koutitas CG (1988). Mathematical Models in Coastal Engineering. 155 p. Pentech Press. London.

NIGS (1999). Assessing the water quality of Laguna de Bay using the sediment record. National Institute of Geological Sciences, UP Diliman, Quezon City. Technical Report Submitted to Laguna Lake Development Authority. 
Rivera PC (1997). Hydrodynamics, sediment transport and light extinction off Cape Bolinao, Philippines. 244 p. Balkema Press, The Netherlands.

Van der Kaaij, T., Hernandez, E.C. \& Rivera, P.C. (2001). Set-up of the Delft3D Hydrodynamic Model for Laguna de Bay. Technical Report. Submitted to Laguna Lake Development Authority, Philippines.

Van Rijn LC (1993). Principles of sediment transport in rivers, estuaries and coastal seas. Aqua Publications. Amsterdam, The Netherlands.

Van Rijn LC (2005). Sedimentation and erosion engineering in rivers, estuaries and coastal seas. Amsterdam, The Netherlands.

WL | Delft Hydraulics, Delft3D-Flow User Manual (1995). 